\title{
Islas y penínsulas anafóricas: gramática y pragmática
}

\author{
Anaphoic islands and peninsulas: grammar and pragmatics
}

\section{Antonio Fábregas}

Universidad de Tromsø. Correo electrónico: antonio.fabregas@uit.no

\begin{abstract}
Los conceptos de isla anafórica (Postal 1969) y península anafórica (Corum 1973) han recibido mucha atención en los estudios de la relación entre sintaxis y morfología. En este trabajo, nos concentramos en las penínsulas anafóricas más comunes y exploramos los factores morfológicos, sintácticos y semánticos que hacen posible la península anafórica. Defendemos que las penínsulas anafóricas son efectos discursivos, legitimados por la pragmática, y en los que no se da en realidad una relación de correferencia entre la base de la palabra y un pronombre externo. Nuestro análisis conecta los factores que favorecen esta referencia con aspectos discursivos y semánticos, aportando de esta manera evidencia adicional a los análisis que tratan estos casos como efectos discursivos.
\end{abstract}

Palabras clave: isla anafórica, península anafórica, factores discursivos, transparencia morfológica, nombres propios.

Concepts such as anaphoric island (Postal 1969) and anaphoric peninsula (Corum 1973) have been part of the studies on the relationship between morphology and syntax, where they have received a great deal of attention. In this article we analyze the most common anaphoric peninsulas, exploring their morphological, syntactic and semantic conditions. We argue that anaphoric peninsulas are actually the effect of pragmatic and discoursive factors, as there is no real coreference between the base of the word and an external pronoun. Our analysis connects all the factors that favour this kind of reference with semantic and discoursive aspects, thus providing additional evidence that these effects are actually pragmatic and not structural.

Key words: anaphoric island, anaphoric peninsula, discoursive factors, morphological transparency, proper names.

\section{INTRODUCCIÓN}

Desde el trabajo de Postal (1969), se ha observado que las palabras son generalmente islas anafóricas que no permiten referencia pronominal a un elemento interno a ellas, como en (1), ni pueden hacer referencia a un elemento externo, como en (2): 
(1) a. * Los [lava[platos $\left.]_{\mathrm{i}}\right]$ antiguos no los lavan muy bien.

b. *Compré un [para[sol] $]_{\mathrm{i}}$ ] para cuidarme de él.

(2) a. *Para lavar los platos ${ }_{\mathrm{i}}$ me he comprado un [lava[los $\left.]_{\mathrm{i}}\right]$

b. *El actual presidente ${ }_{\mathrm{i}}$ ha conocido al ex él ${ }_{\mathrm{i}}$

Estos dos fenómenos no son equivalentes ni se han considerado igualmente problemáticos. Concretamente, en cuanto a los casos mencionados en (2), se ha dicho (Sproat 1988) que la agramaticalidad de estos casos podría deberse a la imposibilidad de construir compuestos productivamente con pronombres, o más en general incluso, a la imposibilidad de tener proyecciones gramaticales en el interior de las palabras (cf. Baker 1988). Asimismo, bien podría pensarse que prefijos como ex requieren combinarse con ciertas categorías gramaticales -particularmente, sustantivos- y no admiten combinaciones con pronombres (Montermini 2006).

En cambio, el caso ilustrado en (1) ha atraído la atención de los investigadores en morfología, sintaxis y semántica, que han observado las implicaciones que esta clase de datos tienen para aspectos tales como la autonomía de la morfología con respecto a la sintaxis o el nivel de la gramática donde debe tratarse propiamente la correferencia pronominal (cf. Cornish 2005; Dressler 1987; Felíu 2002; Harris 2006, entre otros muchos).

Las islas anafóricas parecen tener algunas excepciones, que han sido tratadas repetidamente en la literatura y han recibido el nombre de 'penínsulas anafóricas', para marcar el hecho de que, aparentemente, admiten ciertas correferencia externa (Browne 1974; Corum 1973). En esta sección recordaremos los casos fundamentales y trataremos de mostrar por qué no pueden considerarse propiamente excepciones, sino que requieren un tratamiento pragmático-discursivo.

1.1. El primer conjunto de excepciones se refieren a casos como los de (3), notados por Lieber (1992) para el inglés.

(3) Los aznaristas ya no creen en él.

En (3) parece posible interpretar él como referido a Aznar. La interpretación que hace Lieber de este fenómeno es que el pronombre tiene acceso al nombre propio Aznar, usado como base del sufijo -ista en aznarista. Habría, pues, correferencia directa entre un pronombre y un elemento interno de una palabra.

El segundo caso donde parece que un elemento anafórico (aunque esta vez, de naturaleza adverbial) tiene acceso a un elemento interno a una palabra es el tipo ilustrado en (4), que debemos a Varela (1990).

(4) En verano, los castellanos viajan a Cataluña y viceversa.

En este caso, viceversa parece interpretarse como 'los catalanes viajan a Castilla'. Esto parecería sugerir que, como mínimo, el adverbio viceversa tiene acceso a la base que toma el sufijo - ano para formar la palabra castellano, que es el nombre propio Castilla.

Los dos fenómenos no son idénticos, como mostraremos a continuación. 
1.1.1. Para los casos de (3), ha habido una polémica que ha reinterpretado los datos de forma diferente a como lo hizo Lieber. Según el análisis alternativo, el pronombre no tiene acceso a la base de la derivación, sino más bien a un referente discursivo, introducido pragmáticamente, que remite a Aznar, igual que el nombre propio Aznar que está en la base de la palabra.

Dicho de otro modo: en la oración de (3) el pronombre puede aludir a Aznar porque este referente se encuentra activo de alguna manera en el contexto discursivo, con independencia de que se use el nombre propio de esta persona en un sustantivo derivado. Hay diversas pruebas formales que pueden mostrar, de hecho, que el pronombre no se refiere al nombre propio contenido en el sustantivo aznarista. Reproduciremos dos de ellas.

La referencia entre un pronombre y su antecedente tiene ciertas restricciones sintáctico-semánticas. Una de ellas es que un pronombre no puede referirse a un nombre propio que lo siga en la oración. Esta restricción, que ha sido analizada teóricamente por algunos autores como una violación del Principio C de la teoría del ligamiento (Lebeaux 2009), da lugar a que, sin focalizaciones y con entonación normal, en la oración de (5), el pronombre ella no puede referirse a Marta, porque este referente está tomado por el nombre propio Marta, que aparece después del pronombre.

(5) Ella piensa que Marta es muy inteligente.

Es posible alterar los valores discursivos de los elementos de esta oración para hacer posible la correferencia (por ejemplo, focalizando el pronombre: Ella misma piensa que Marta es muy inteligente), pero el hecho es que la oración de (5) no admite esta interpretación sin dichas focalizaciones. Compárese ahora (5) a (6), donde según la propuesta de Lieber tendríamos correferencia.

(6) Él ya no cree en los aznaristas.

Esta oración, en cambio, sí permite que el referente del pronombre él sea Aznar. Si el pronombre se refiriera directamente al nombre propio Aznar, contenido en el sustantivo aznarista, estaríamos reproduciendo el esquema de correferencia de (5) y por ello esperaríamos que la correferencia estuviera bloqueada, al igual que lo está en (5). Sin embargo, la correferencia es perfectamente posible, lo cual indica que en (6) -y por lo tanto en (3), donde se da la misma relación de significado- no podemos tener el mismo tipo de referencia que en (5). El caso de (6), pues, no puede ser un caso de correferencia entre un pronombre y un elemento interno a una palabra.

En segundo lugar, eliminando casos asimilables a la concordancia por el sentido, un pronombre debe coincidir en género y número con su antecedente. En (7), el pronombre sujeto no puede referirse al sustantivo el niño sencillamente porque el pronombre es plural y el sustantivo es singular.

(7) Ellos no piensan que el niño esté sano.

Sin embargo, en casos como los de (3) es posible que el pronombre sea plural y se interprete como referido a la misma entidad que denota la base del sustantivo. Véase (8): 
(8) ? Los monarquistas de todo el mundo ya no creen en ellos.

Ciertamente, la oración no es perfecta, pero admite la interpretación en que ellos se refiere a los reyes que hay en el mundo y, por lo tanto, la oración indica que las personas que apoyan a la monarquía han perdido la fe en sus monarcas. Esta interpretación está disponible en (8), aunque marginalmente, pero el mismo tipo de discordancia en número hace la correferencia completamente imposible en (7). Esta interpretación indica que en (8) la referencia del pronombre no puede ser la base de la palabra monarquista, porque dicha base (monarca) no sería plural y, por lo tanto, nos forzaría a tener el mismo tipo de discordancia de número que tenemos en (7), donde esta diferencia impide automáticamente que el pronombre ellos correfiera con el niño. En cambio, si el pronombre se refiere a un referente discursivo, 'los monarcas del mundo', activado en el contexto por medio de algún procedimiento que precisaremos en el resto del artículo, la correferencia puede explicarse de forma simple.

1.1.2. En el caso de viceversa, este adverbio se limita a darle al hablante instrucciones para que invierta la relación conceptual que se expresa en la oración anterior, de tal manera que obtenga una lectura recíproca. En la oración de (4), viceversa indica que recíprocamente los habitantes de un lugar viajan a otro lugar; en la oración de (9), indica que la relación que se establece entre el sujeto y el objeto también se produce recíprocamente entre el objeto y el sujeto; en (10), invierte la relación entre la oración subordinada temporal y la principal.

(9) Juan quiere a María y viceversa.

(10) María se enfada cuando Pedro habla y viceversa.

Nuestra propuesta es que la aportación del adverbio viceversa actúa en el nivel conceptual, pero no en un nivel sintáctico, por lo que oraciones como (4) no demuestran que la sintaxis tiene acceso a la estructura interna de la palabra. Una prueba de que viceversa aporta instrucciones semánticas, pero no sintácticas, es que de hecho el adverbio no requiere que los conceptos que han de entenderse recíprocamente se manifiesten gramaticalmente en la estructura de la oración anterior. Véase (11).

(11) Cuando uno es soltero siempre quiere tener novia y viceversa.

En esta oración, viceversa se interpreta como 'Cuando uno está emparejado quiere no tener novia', pero naturalmente la palabra emparejado (u otra equivalente que el lector quiera sobreentender en su glosa del adverbio) no está expresada gramaticalmente en la oración anterior, por lo que no cabe hablar de que viceversa busque su referencia en los constituyentes estructurales de la oración previa. Su aportación actúa en un nivel puramente conceptual, invirtiendo las relaciones semánticas que se despiertan en la mente el hablante al leer la primera oración e indicando que debe interpretarlas de forma recíproca. (12) muestra otro ejemplo de esto mismo, donde se ve con claridad que lo que se invierte son conceptos que no se manifiestan como constituyentes sintácticos propios. 
(12) Para descansar, los pintores prefieren ir a conciertos y viceversa.

En este caso, y viceversa se interpreta normalmente como 'los músicos prefieren ir a exposiciones', pero claramente ninguno de estos sustantivos están mencionados en la estructura anterior: los conceptos expresados por ellas, sin embargo, se activan en la mente del hablante al leer la primera oración, y esto ya es suficiente para que funcione la contribución semántica del adverbio viceversa.

1.1.3. Por lo tanto, parece que en ninguno de los dos casos de aparente península anafórica puede hablarse de correferencia al interior de la palabra en sentido estricto. En ambos casos, son factores pragmáticos y semánticos los que hacen posible que se produzca la interpretación relevante, pero las construcciones no tienen las propiedades que se espera de la correferencia pronominal manifestada sintácticamente.

Si esta interpretación de los datos es correcta, ha de ser posible estudiar en qué condiciones discursivas y semánticas se pueden producir estos efectos, especialmente en casos como los de (3). En las próximas secciones revisaremos factores morfológicos, sintácticos y semánticos que facilitan o dificultan las 'penínsulas anafóricas', y defenderemos que siempre pueden reducirse a una cuestión pragmática, lo cual refuerza el análisis pragmático-discursivo que esta primera aproximación a los datos sugiere.

Es necesario hacer una precisión sobre la terminología que vamos a emplear en el trabajo. Ya que los datos que hemos presentado en $\S 1.1 .2$ muestran que no cabe hablar de correferencia en sentido estricto, utilizaremos el término'referencia compartida'. Con este término tratamos de indicar que el pronombre externo a la palabra puede referir al mismo concepto al que normalmente alude la base de la palabra compleja, aunque esta coincidencia no se produce de manera directa, con el pronombre refiriendo directamente a la base.

No todos los casos de referencia compartida son igualmente posibles. Si bien en (3) es posible que haya referencia compartida entre el pronombre y la base de la palabra que forma el sujeto (cf. ejemplo 13a, repetido aquí por comodidad del lector), en (13b) esta misma referencia compartida no se obtiene para la mayor parte de los hablantes.

(13) a. Los aznaristas ya no creen en él.

b. Los aznaristas ya no lo defienden.

En efecto, el pronombre lo para la mayor parte de los hablantes no es interpretable como Aznar en (13b); estos mismos hablantes típicamente admiten que él corresponda a Aznar en (13a).

El resto de este artículo está organizado de la siguiente manera. En el apartado 2 estudiaremos las condiciones morfológicas que hacen posible esta referencia compartida; en §3, hablaremos de las condiciones sintácticas, y en §4, nos concentraremos en los factores semánticos fundamentales.

1.1.4. Antes de seguir adelante, es necesario explicitar un criterio metodológico. En la evaluación de los casos de referencia compartida, tendremos solamente en cuenta aquellas situaciones en que la referencia es posible cuando la oración aparece en posición inicial absoluta de discurso, por ejemplo, como un titular de prensa. Eliminaremos de nuestro estudio, pues, casos como los de (14), en los que la oración 
aparece tras un enunciado previo. La razón es que en estos casos siempre es posible que ya fuera nombrado el referente que toma el pronombre, como en el ejemplo.

(14) Al congreso también vino Aznar. . Los aznaristas que estaban con él ${ }_{i}$ ya han dejado de apoyar- $-\mathrm{lo}_{\mathrm{i}}$.

En estos casos, hay muy poco que decir, y el efecto de península anafórica es claramente accidental, ya que la referencia de él es completamente independiente de la presencia de Aznar como base de una palabra en la oración en la que se encuentra. Por esta razón, los únicos casos que consideraremos durante el trabajo son aquellos en que el enunciado es inicial absoluto, para evitar la posibilidad de que la referencia del pronombre se resuelva como en (14). Estudiaremos todos los enunciados como si fueran titulares dentro de un periódico, y los juicios de gramaticalidad que se dan siempre consideran el ejemplo en este tipo de contexto.

\section{ASPECTOS MORFOLÓGICOS Y SEMÁNTICOS}

Montermini (2006) se concentra en los aspectos morfológicos que favorecen la referencia compartida y detecta una generalización interesante en italiano: cuanto más transparente es la relación morfológica que la base de la palabra establece con la palabra que normalmente se utiliza para referir a ese concepto, más sencillo es establecer la referencia compartida. En un extremo, tenemos casos como los de (15), donde la base de la palabra es regularmente el mismo elemento que se emplea, como palabra independiente, para designar la noción a la que remite el pronombre. En el extremo contrario, tenemos casos como los de (16), donde la base de la palabra es una forma muy distinta. Montermini muestra que los juicios de los hablantes contrastan de forma acorde: a mayor transparencia morfológica, mayor facilidad para obtener la referencia compartida. Nótese que la traducción española no es gramaticalmente comparable a la oración italiana, ya que en el primer caso no tenemos una palabra derivada, sino un grupo nominal.

(15) ?Ho donato tre euro con il telefon ${ }_{i}$-ino e due euro con quello fisico He dado tres euros con el telefon-ito y dos euros con ese físico 'He donado tres euros con el teléfono portátil y dos con el fijo'

(16) *?Ho donato tre euro con il cellulare $\mathrm{i}_{\mathrm{i}}$ e due euro con quello fisico $_{\mathrm{i}}$ He dado tres euros con el celular y dos euros con ese físico '??He donado tres euros con el móvil y dos con el fijo'

Es fácil de mostrar que en español están vigentes los mismos principios de transparencia morfológica cuando se buscan ejemplos gramaticalmente comparables a la situación que discute Montermini (2006). Obsérvense los siguientes ejemplos:

(17) a. Los berluscon -ianos ya no creen en él.

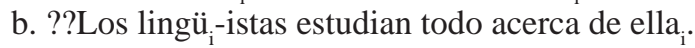

c. *Los lácte ${ }_{\mathrm{i}}$-os se hacen con un poco de ella y otros productos.

d. *Los $\log _{\mathrm{i}}$-pedas se ocupan del estudio de ella. 
En casos como (17a), donde la base de la palabra corresponde al mismo morfema que se utiliza como nombre propio, la referencia compartida se obtiene con mayor facilidad. En cambio, cuando el morfema sufre alguna modificación fonológica, como en (17b), la referencia compartida es más difícil de obtener. En aquellos casos donde se emplean voces grecolatinas, remotamente conectadas históricamente con el término patrimonial (como en 17c) o sin ninguna conexión de evolución fonológica (como en 17d), la referencia compartida se hace imposible en la práctica.

La cuestión es cuál es la forma correcta de interpretar estos datos. Nuestra propuesta, que en este sentido se separa ligeramente de lo que sugiere Montermini (2006), es que la diferencia no se debe directamente a la materialización fonológica de los segmentos implicados, sino a las propiedades semánticas que suelen acompañar a los casos en que no hay una relación morfológica transparente entre dos palabras.

Se ha observado (cf. para un resumen de esto, Pensado 1999) que cuando los morfemas sufren cambios idiosincrásicos obligatorios en su combinación con otras formas, tienden también a perder su significado composicional, y la palabra así formada tiende a interpretarse de una manera especial. Esta correlación está en la base de la teoría de los estratos léxicos (Kiparsky 1982), que muestra que los cambios fonológicos idiosincrásicos vienen acompañados generalmente de alteraciones impredecibles también en el significado de la palabra compleja. Intuitivamente, un hablante medio que se enfrenta a palabras como las de (17c) y (17d) -tal vez también a las de (17b)- no es consciente de la relación histórica que la base de esas palabras guarda con otras palabras, como lengua y leche, ya que generalmente no ha recibido formación en gramática histórica.

Por ello, el hablante medio tiene una tendencia a interpretarlas como todos indescomponibles, y a asociar a ellas a menudo un significado que no es exactamente igual al de las voces con las que los ejemplos de (17c) y (17d) tratan de establecer la correferencia. Un producto lácteo, en sentido estricto, no es un producto que contenga leche (para ello emplearíamos en español, tal vez, el adjetivo lechoso), y un hablante que no tenga formación práctica sobre estos temas puede ignorar perfectamente que el yogur y el queso son productos que se obtienen al tratar la leche de diversos modos.

Una prueba de que lo relevante en la correlación que identifica Montermini no es tanto la materialización morfofonológica del morfema cuanto lo que esto implica para la relación semántica que se establece, es abordar casos en los que la correlación entre impredecibilidad semántica e idiosincrasia morfofonológica no es perfecta y ver qué sucede en estos casos. Entre los ejemplos relevantes, encontramos formaciones como donjuanismo o cristianismo, que están formadas sobre nombres propios cuya forma morfológica es preservada sin cambios idiosincráticos en el interior de la palabra, pero que obtienen interpretaciones semánticas especiales que no se refieren literalmente al individuo que denota el nombre propio. Es decir, el donjuanismo no es el estudio o la exaltación del individuo llamado Don Juan, sino que designa un comportamiento social que reproduce lo que prototípicamente se identifica con el comportamiento de ese personaje; el cristianismo no es el estudio de la vida de Cristo, sino la adhesión a una serie de valores que prototípicamente se identifican con esta persona. En casos como estos, donde hay una discrepancia entre la forma de la base -que se preserva- y su significado - que no se preserva-, nuestra explicación y la de Montermini hacen predicciones distintas: Montermini prediría que la referencia compartida estaría facilitada, porque la forma se mantiene, mientras que nuestra 
interpretación de los datos prediría lo contrario, porque no hemos mantenido el significado. Véase el ejemplo (18), donde se muestra que en estos casos la referencia compartida es prácticamente imposible, confirmando nuestra interpretación.

(18) *El ddonjuan $_{\mathrm{i}}$-ismo / crist-ian-ismo $\}$ no es el estudio de él. ${ }_{\mathrm{i}}$.

La explicación adecuada es, a la luz de estos datos, de base semántica más que morfológica: trivialmente, para que el pronombre y la base puedan referirse a la misma entidad, es necesario, para empezar, que el hablante interprete la base de la palabra de la misma forma que normalmente la interpreta cuando aparece aislada: para que haya referencia compartida, Don Juan debe referirse al individuo Don Juan, y Cristo, a Cristo. Volveremos sobre esto en $\S 4$.

En la siguiente sección pasaremos a discutir los contextos sintácticos que favorecen o dificultan la referencia compartida, y defenderemos que una explicación de corte semántico y pragmático es, en este caso también, la correcta.

\section{CONTEXTOS SINTÁCticos}

Dependiendo del papel sintáctico que desempeñe el elemento pronominal, la referencia compartida puede resultar más o menos sencilla en español. Obsérvense los contrastes de (19).

(19) a. *?Los aznar-istas ya no lo $_{\mathrm{i}}$ aguantan.

b. *?Los aznar-istas ya no le $\mathrm{i}_{\mathrm{i}}$ dan crédito.

c. Los aznar-istas ya no creen en él.

El contraste fundamental cuando ambos elementos están en la misma oración es el que se establece entre los pronombres introducidos por preposición y aquellos que no lo están, como se muestra en (19). Tanto (19a) como (19b), sin preposición, resultan más difíciles que (19c), con preposición.

El ejemplo de (20) muestra que, cuando el pronombre está en el mismo sintagma nominal que el antecedente, como uno de sus modificadores -por ejemplo, en una oración subordinada de relativo- la referencia compartida es muy difícil de obtener incluso si el pronombre está introducido por una preposición.

(20) *[Los aznar ${ }_{i}$-istas que vinieron con él $\left.{ }_{i}\right]$ organizaron una conferencia.

Sin embargo, en otras situaciones estar en el interior de una oración subordinada facilita la referencia compartida. La asimetría es en esta ocasión ligeramente distinta: cuando el pronombre ocupa la posición de sujeto, la correferencia se facilita; cuando ocupa la posición de objeto sin preposición, no.

(21) a. Los aznar ${ }_{i}$-istas piensan que él ya no es de fiar.

b. *?Los aznar-istas creen que ya no pueden aguantar-lo más.

c. *?Los aznar-istas votarían a otro partido si no pudieran aguantar-lo más. 
La cuestión es cómo se puede explicar este patrón de datos que parece, en principio, confuso, y si puede reducirse a un patrón discursivo, como prediría el análisis que defendemos sobre las penínsulas anafóricas.

Como es bien sabido, las funciones sintácticas se asocian prototípicamente a distintas funciones informativas a través del orden no marcado de palabras y otros factores gramaticales. Normalmente, un cambio de orden en dichas funciones se correlaciona con una alteración equivalente de dichas funciones discursivas.

Generalmente, en español el sujeto tiene la función de tópico discursivo y generalmente -salvo en los casos en que se introduce un tópico contrastivo, que explicaremos más adelante- enlaza con el discurso precedente indicando el tema sobre el que pivota el enunciado (Contreras 1976; Zubizarreta 1998). De esta manera, en una oración como (22), emitida en situaciones normales y con un orden de palabras no marcado, el sujeto refleja el tema del enunciado.

(22) [Los aznaristas] han rechazado al nuevo candidato.

Es, por lo tanto, el sujeto el que introduce el referente discursivo sobre el que trata el resto del enunciado. Ahora bien: para conseguir que un pronombre contenido en algún punto del resto de la oración se ligue discursivamente con otro referente discursivo no citado en el discurso anterior -recuérdese que consideramos solo aquellos casos en que no hay discurso previo-, distinto de aquel que introduce el sujeto, es necesario que de alguna forma se marque un contraste con el tópico introducido por el sujeto. Una de las formas de marcar este contraste explícitamente es situando al siguiente elemento en posición final de oración -generalmente reservada para los focos contrastivos en español- y emplear algún marcador discursivo, como en (23).

(23) Los aznaristas han rechazado al nuevo candidato, pero, en cambio, lo han apoyado los democristianos.

Esta necesidad de introducir un contraste resulta crucial para explicar los casos de referencia compartida que hemos presentado al comienzo de esta sección. Para obtener la referencia compartida es necesario que el tópico discursivo deje de ser la entidad denotada por el sujeto y pase a ser otro referente presente de alguna forma en el contexto, con el que necesariamente se ha de establecer un contraste. En un ejemplo como (3), repetido aquí como (24), para que el pronombre él pueda referirse a Aznar es necesario que el tópico discursivo pase de ser 'los aznaristas' a 'Aznar', y para ello es necesario que haya un mecanismo que permita que el pronombre sea interpretado contrastivamente. Sin dicho contraste, el pronombre no podrá cambiar el tópico del discurso y la oración no será interpretable con referencia compartida.

Con esta guía, es posible entender los casos en que la referencia compartida es posible y aquellos en que no lo es. Comencemos con el caso de (20), repetido aquí como (24):

(24) *[Los aznar ${ }_{i}$-istas que vinieron con él $\left.{ }_{i}\right]$ organizaron una conferencia.

En este caso, el pronombre que debe referirse a Aznar, activado discursivamente, está en el mismo constituyente gramatical que el tópico de la oración, los aznaristas. Ya que existe una correlación entre el orden de palabras, las funciones sintácticas y 
el papel discursivo de cada elemento, es imposible que el mismo constituyente -en este caso, el sujeto- sea a la vez tópico y foco contrastivo. Ya que el sujeto antepuesto al verbo es tópico, el constituyente entre corchetes se interpreta como tal y no es posible que una parte de él sea un foco dentro de la oración. Por lo tanto, al no ser posible establecer un contraste y un cambio de tópico en el interior del constituyente, la referencia compartida no se puede producir.

Este ejemplo contrasta con (21a), repetido aquí como (25), donde la referencia compartida es simple de obtener.

(25) Los aznar ${ }_{i}$-istas piensan que él ${ }_{i}$ ya no es de fiar.

Aquí hay dos cambios sustanciales, que justifican que ahora sea posible obtener esta referencia. La primera es que el pronombre no está en el mismo constituyente sintáctico que el sujeto los aznaristas. De hecho, ahora cada uno de ellos es un sujeto diferente dentro de una oración diferente. En segundo lugar, se emplea un pronombre explícito para actuar como sujeto. Es bien sabido que en español, la presencia del pronombre explícito en función de sujeto suele tener un efecto contrastivo; en efecto, la oración de (26) sugiere que el grupo de personas que incluye al hablante se contrasta con otro grupo dentro del discurso, frente a (27), sin sujeto explícito, donde este contraste no se establece.

(26) Nosotros hemos entregado el informe ya.

(27) Hemos entregado el informe ya.

Así pues, en (25) los factores discursivos y gramaticales son óptimos para permitir al pronombre referirse a un referente discursivo distinto de aquel que introduce el sujeto de la oración principal. La predicción es que la referencia compartida será más difícil de obtener cuando estos factores favorecedores falten. En efecto, como se ve en (28), cuando el sujeto de la oración subordinada no es un pronombre explícito, sino que está -en términos tradicionales- sobreentendido o es una categoría tácita, la referencia compartida es mucho más difícil de obtener. Esto se debe a que, al igual que en (27), no hay una marca gramatical de contraste.

(28) Los aznaristas piensan que ya no es de fiar.

Otros casos pueden ser explicados mediante la correlación que se establece entre la forma de los pronombres y su papel discursivo. Se ha observado repetidamente que los pronombres átonos no son capaces de contrastar en el discurso (Fernández Soriano 1999), y no pueden ser foco del enunciado, mientras que los pronombres tónicos pueden serlo. En (29) observamos un caso en que se muestra este efecto: una pregunta siempre establece un contexto contrastivo, porque mediante la interrogación el hablante presenta un conjunto implícito de posibles respuestas. Cuando el hablante responde, dicha respuesta siempre es contrastiva, ya que selecciona del interior de dicho conjunto una parte de él, y manifiesta que la respuesta que el resto de elementos del conjunto no son respuestas válidas. Pues bien: a la pregunta de (29) es posible responder con un pronombre tónico (30a), pero no mediante uno átono (30b). 
(29) ¿A quién viste?

(30) a. A él / a ella

b. ${ }^{*} \mathrm{Lo} / *$ la

Igualmente, los pronombres átonos rechazan el acento contrastivo, sobre todo cuando son proclíticos, mientras que los tónicos no lo rechazan. La oración de (31a) se puede entender como que el hablante quiere dejar claro que, frente a lo que se suponía en el contexto -que vio a Marta-, la persona a la que vio fue otra - por ejemplo, Ana-, pero no es posible utilizar (31b) en este mismo sentido. En (31), como es habitual, marcamos el acento contrastivo escribiendo la palabra en mayúsculas.

(31) a. La vi a ELLA. b. *LA vi a ella.

Teniendo en cuenta esta diferencia, obsérvese cómo podemos explicar la facilidad con la que se obtiene la referencia compartida en (19c) -repetido como (32)- frente a la dificultad con la que esta se obtiene en $(19 a, b)$ y $(21 b, c)$-repetidos como (33a, b) y (34a, b), repectivamente-.

(32) Los aznar ${ }_{i}$-istas ya no creen en él ${ }_{\mathrm{i}}$.

(33) a. *?Los aznar-istas ya no lo aguantan. b. *?Los aznar ${ }_{\mathrm{i}}$-istas ya no le $\mathrm{e}_{\mathrm{i}}$ dan crédito.

(34) a. *?Los aznar-istas creen que ya no pueden aguantar-lo más.

b. *?Los aznar ${ }_{i}$-istas votarían a otro partido si no pudieran aguantar-lo más.

En todos los casos, cuando el pronombre que trata de hacer la referencia compartida es átono, ésta se ve dificultada, pero cuando es tónico, resulta más simple de obtener. La razón es que el requisito de contraste que requiere la construcción se puede satisfacer mediante un pronombre tónico, pero un pronombre átono, al no poder ser contrastivo, no tiene esta capacidad. La predicción es que, si modificamos las oraciones de (33) y (34) de tal manera que el complemento pueda ser contrastivo, la referencia compartida podrá obtenerse. Una forma de conseguir esto es mediante una construcción de doblado de clítico, en la que el pronombre átono aparezca acompañado de un pronombre tónico. En (35) vemos que, efectivamente, esta estrategia funciona, lo cual incide en la idea de que el contraste es imprescindible para obtener esta referencia compartida.

(35) a. ?Los aznaristas ya no lo aguantan a él.

b. ?Los aznaristas ya no le dan crédito a él.

c. ?Los aznaristas creen que ya no pueden aguantarlo más a él.

d. ?Los aznaristas votarían a otro partido si no pudieran aguantarlo más a él.

Aunque no son perfectas, estas secuencias admiten la referencia compartida con algo más de facilidad que sus correspondientes formas sin pronombre tónico. 
3.1. Otros condicionantes son puramente discursivos y se reflejan en que ciertas bases morfológicas expresan individuos con más facilidad que otras, que expresan más bien predicados que pueden aplicarse a muchas entidades diversas. No olvidemos que los casos que estamos estudiando aquí son aquellos en que la oración podría ser principio absoluto de discurso, ya que hemos descartado -por ser perfectamente predecibles- los casos en que el antecedente se encuentra en una oración anterior. Por tanto, los casos en los que nos estamos concentrando son aquellos en los que la oración podría ser, por ejemplo, el titular de un periódico. Consideremos exclusivamente estos casos y veamos el contraste de (36).

(36) a. El zapater-ismo no puede seguir sin él.

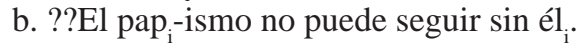

Ambas oraciones son paralelas en su forma sintáctica -por lo que descartamos los factores presentados en el apartado anterior- y en su manifestación morfológica, ya que la manifestación del nombre propio Zapatero en el interior de la palabra es tan trasparente como la del sustantivo Papa: en ambos casos solamente desaparece la desinencia final átona. ¿Cuál es, pues, la razón por la que la referencia compartida de (36a) resulta más natural que la de (36b)?

Nuestra propuesta es la siguiente: para garantizar que el referente discursivo sea parte del contexto activo, los nombres propios -como la base en (36a)- tienen una serie de peculiaridades que los nombres comunes, como los referidos a cargos aunque esos cargos sean únicos en un momento determinado, como sucede en (36b)-, no poseen. Estas peculiaridades hacen que el referente pueda activarse de forma más sencilla con los nombres propios que con cualquier nombre común.

En primer lugar, los nombres propios en español estándar pueden aparecer sin determinante, mientras que los nombres de cargos -aunque estos sean únicos- no.

(37) a. Zapatero inauguró la convención.

b. *(El) Papa inauguró la convención.

c. *(El) Rey inauguró la convención.

d. *(El) presidente inauguró la convención.

Por esta razón, cuando aparecen solos, los nombres propios pueden referirse a individuos particulares, mientras que sin determinante los nombres de cargos aluden al cargo específico, pero no a la persona que lo ocupa. De aquí se sigue que, cuando aparecen obligatoriamente sin determinante, como es el caso cuando la forma es la base de una palabra compleja, el nombre propio pueda seguir denotando individuos, pero el nombre de cargo no aluda a tal. Contrástese (38) y (39).

(38) a. (decreto) salva-Berlusconi

b. zapater-ismo

c. juancarl-ismo

(39) a. presidenc-ial-ismo

b. pap-ismo

c. (decreto) anti-Rey 
En los ejemplos de (38), con nombres propios, se entiende de forma clara que la base se refiere al individuo particular. Un decreto salva-Berlusconi no es un decreto que salve a cualquier primer ministro corrupto, sino uno exclusivamente dirigido a salvar a Berlusconi. El zapaterismo es el apoyo a Zapatero, y no a cualquier otro presidente español o miembro del partido socialista, y una persona que profesa el juancarlismo en España no es una persona que apoye a cualquier rey español o que esté a favor de la monarquía, sino que está a favor de que el individuo particular llamado Juan Carlos de Borbón sea jefe de Estado. Esta diferencia es culturalmente muy marcada y en la sociedad española se suele hacer una distinción entre monarquistas, que apoyan a cualquier rey español porque consideran que la monarquía es una forma política preferible, y juancarlistas, muchos de ellos republicanos, pero que apoyan al individuo particular.

Normalmente, cuando la base de la palabra es un nombre propio, ésta alude directamente al individuo, salvo en aquellos casos donde la palabra es de uso muy frecuente, antigua y la lexicalización ha ido muy lejos; en tales casos (40), la base se refiere a la ideología asociada prototípicamente con la persona a la que refería el nombre propio, y en estos casos la referencia compartida tampoco se obtiene fácilmente (41; recuérdese el ejemplo de donjuanismo mencionado en §2).

(40) a. marx-ismo

b. dant-esco

c. bud-ismo

(41) a. ??Los bud-istas han leído todos los textos atribuidos a él.

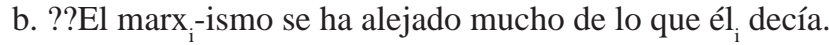

En los casos de (41) sucede lo que en (39): las bases no refieren ya a individuos particulares, por lo que no pueden usarse para activar el referente discursivo que se espera que tome el pronombre, al contrario de los casos de (38). Un decreto anti-Rey se interpreta como un decreto que ataca a la monarquía y no al individuo particular que en ese momento es Rey. Lo mismo se puede decir de papismo, ya que quien se considera papista apoya al Papa, sea quien sea este, y de presidencialismo, pues esta ideología apoya a los presidentes de la República por encima de las diferencias individuales.

En esta sección hemos tratado de encontrar una explicación que conecte el estatuto especial de los nombres propios para la referencia compartida con el resto de datos que hemos ido observando en estas páginas. Nuestra propuesta es que los nombres propios son más frecuentes porque, sin determinante y como base de la formación de palabras, ya denotan individuos, y por eso pueden utilizarse para activar un referente discursivo individual en contextos tales como un titular de prensa.

\section{CONCLUSIONES}

En esta pequeña contribución hemos tratado de aportar pruebas de que los aparentes casos de península anafórica documentados en la bibliografía son sistemáticamente casos pragmáticos en los que el pronombre y la base de una palabra coinciden en aludir al mismo referente, pero sin establecer directamente correferencia entre ellos. Hemos mostrado que el comportamiento de estos casos en su interacción con la 
morfología, la sintaxis y el discurso es precisamente el que se espera si la referencia se obtiene mediante procesos pragmático-semánticos y no propiamente sintácticos. Hemos observado ciertas tendencias, todas ellas explicables mediante simples reglas pragmáticas:

a) La referencia compartida es más fácil cuanto más trasparente es la relación morfológica que la base de la palabra mantiene con su forma libre.

b) La referencia compartida es más fácil cuanto más trasparencia semántica haya en el significado de la palabra.

c) La referencia compartida es más fácil cuantos más procedimientos gramaticales de contraste se asocien al pronombre, sea por su clase pronominal (pronombre tónico) o sea por su posición sintáctica (posición final de oración).

d) La referencia compartida es más fácil cuando la base, sin determinantes, puede referir a un individuo, como sucede con los nombres propios.

\section{OBRAS CITADAS}

Baker, M. 1988. Incorporation: A Theory of Grammatical Function Changing. Chicago: University of Chicago Press.

Browne, W. 1974. "On the topology of anaphoric peninsulas”. Linguistic Inquiry 5: 612-620.

Contreras, H. 1976). A theory of word order with special reference to Spanish. Amsterdam/ Oxford/New York: North Holland Publishing Company.

Cornish, F. 2005. "Degrees of indirectness: Two types of implicit referents and their retrieval via unaccented pronouns”. A. Branco et al. (Eds.). Anaphora processing: Linguistic, Cognitive and Computational Modelling. Amsterdam/Philadelphia: John Benjamins. 199-220.

Corum, C. 1973. “Anaphoric peninsulas”. Papers from the 9th Regional Meeting. Chicago: Chicago Linguistic Society. 89-97.

Dressler, W. 1987. “Morphological islands: Constraint or Preference?”. R. Steele y T. Threadgold (Eds.), Language Topics. Essays in Honour of Michael Halliday. Amsterdam/Philadelphia: John Benjamins. 71-79.

Felíu, E. 2002. "La opacidad sintáctica de las palabras derivadas: una nueva perspectiva”. Estudios de Lingüística 16: 5-46.

Fernández Soriano, O. 1999. "El pronombre personal. Formas y distribuciones. Pronombres átonos y tónicos”. Ignacio Bosque y Violeta Demonte (Dirs.), Gramática Descriptiva de la Lengua Española. Madrid: Real Academia Española- Espasa (Colección Nebrija y Bello). 1209-1275.

Harris, Alice C. 2006. "Revisiting anaphoric islands”. Language 82: 114-130.

Kiparsky, P. 1982. "Lexical phonology and morphology”. In-Seok Yang (Ed.), Linguistics in the Morning calm. Seúl: Hanshin. 3-91.

Lebeaux, D. 2009. Where does binding theory apply? Cambridge: MIT Press.

Lieber, R. 1992. Deconstructing morphology. Chicago: University of Chicago Press.

Montermini, F. 2006. "A new look on word-internal anaphora on the basis of Italian data". Lingue e Linguaggio 5: 127-148.

Pensado, C. 1999. “Morfología y fonología. Fenómenos morfofonológicos”. Ignacio Bosque y Violeta Demonte (Dirs.), Gramática Descriptiva de la Lengua Española. Madrid: Real Academia Española-Espasa (Colección Nebrija y Bello). 4423-4505.

Postal, P. 1969. “Anaphoric islands”. Papers from the Fifth Regional Meeting. Chicago: Chicago Linguistic Society. 205-239. 
Sproat, R. 1988. “On anaphoric islanhood”. M. Hammond y M. Noonan (Eds.), Theoretical Morphology: Approaches in Modern Linguistics. San Diego: Academic Press. 291-301.

Varela, S. 1990. Fundamentos de morfología. Síntesis, Madrid.

Zubizarreta, M. L. 1998. Prosody, focus and word order. Cambridge: MIT Press. 
